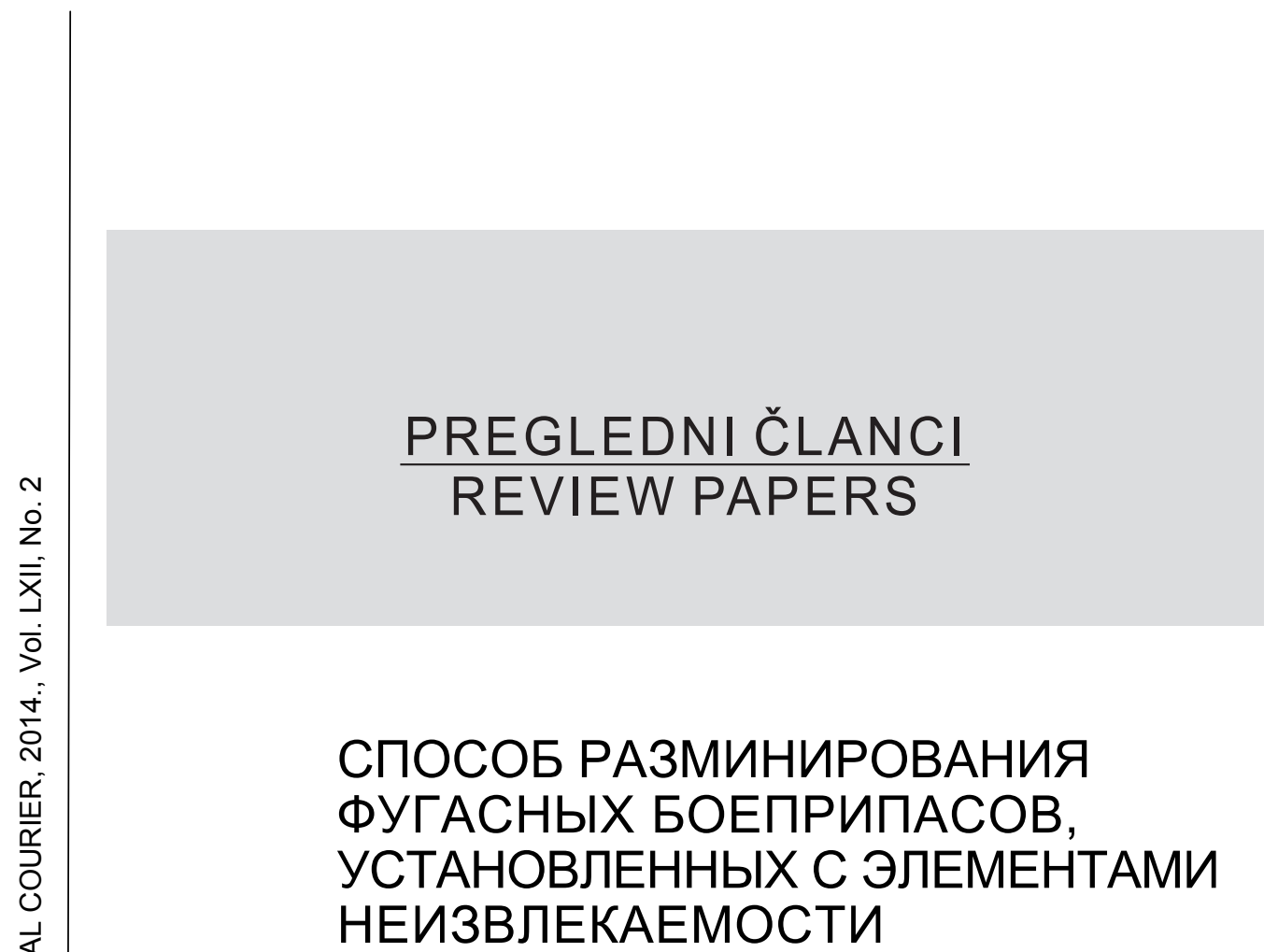

\author{
Александар Иванович Голодяев \\ Соискатель на звание кандидат наук в ВГТУ, \\ г. Воронеж, Россия
}

ОБЛАСТЬ: материалы

ВИД СТАТЬИ: обзорная статья

DOI: 10.5937/vojtehg62-4741

\begin{abstract}
Краткое содержание:
\end{abstract}
Применение способа разминирования вымыванием взрывчатого вещества растворителем позволяет сохранить больщие материальные ценности, снижает риск для пиротехников, связанный с перемещением боеприпаса к месту утилизации. Затраты на специальное оборудование незначительны. Технология легко поддается автоматизации, за счет электронного и телеуправления процессом сверления на расстоянии, что снижает риск подрыва пиротехников к минимуму.

Способ будет эфрфективен в зонах действия против партизанской минной войны.

Ключевые слова: фругасные боеприпасы, разминирование.

звестно достаточно большое число способов разминирования. В особую группу относят способы разминирования боеприпасов установленных с элементами без извлечения (Матвейчук, 2005, стр.512). Самые неудобные для разминирования боеприпасы, изготовленные в кустарных непромышленных условиях. Система минирования этими боеприпасами зависит только от франтазии и знаний изготовителей этих боеприпасов. Опыт 1 и 2 Чеченской войны показал, что кустарные боеприпасы, особенно фугасы, изготовленные из бидонов из-под молока объемом до 40 литров, обычные ведра, и т. д. 
наиболее опасны. Часто в них ставят систему без извлечения по принципу «колокольчика». Обычно их уничтожают на месте обнаружения. Очень часто это ведет к большим материальным потерям (мосты, горные дороги, здания, и др.). Иногда взрывотехникам попадают боеприпасы времен 1 и 2 Мировой войны. Некоторые авиабомбы имеют механизм замедления взрыва, который в момент падения просто остановился. Имеют взрыватели, проржавевшие с капсюлями- детонаторами с повышенной чувствительностью. От старости ТНТ выделяет особую жидкость, имеющую повышенную чувствительность (Шидловский, 1973). Перемещение таких боеприпасов опасно.

Для исключения преждевременного взрыва можно применить способ удаления взрывчатого вещества из корпуса боеприпаса (Обоснование необходимости утилизации списанных боеприпасов: http://do.gendocs.ru/docs/index-339053.html?page=2).

Известно, что почти все взрывчатые вещества можно растворить в специальных растворителях. Например:

1. Все селитры и бертолетовая соль прекрасно растворяются в воде. При этом насыщенный раствор этих веществ невозможно заставить гореть или сдетонировать.

2. Тротил (тринитротолуол или ТНТ) прекрасно растворяется в органических растворителях. Например, бутилацетат, ацетон, дихлорэтан, трихлорэтилен, и др. (Мингулина, Масленникова, Коровин, 1990).

Автор сам, для изготовления муляжа гранаты в коллекцию растворил бутилацетатом ТНТ из гранаты Ф-1 (производства 1940 года) за 10-15 минут, после чего раствор вылил из корпуса гранаты и утилизировал его.

Методика разминирования.

Боеприпас очищают от грунта. Устанавливают на его корпусе ванночку для охлаждающей жидкости. Она может быть из пластилина и не должна пропускать жидкость для охлаждения между ванночкой и корпусом. Жидкость для охлаждения берется по составу для конкретного металла, из которого сделан корпус боеприпаса. Обычно это смесь СОЖ из воды, мыла и минерального масла. Устанавливается сверлильный инструмент со сверлом и кронштейном крепления к корпусу боеприпаса. Часто это магнитное крепление, или струбцина. Сверло не должно вращаться быстрее 60 оборотов в минуту. И режущая часть сверла всегда залита СОЖ для исключения малейшего нагрева режущей кромки сверла. Когда сверло просверливает до взрывчатого вещества, весь инструмент удаляют. В отверстие вводится специальный щуп в фрорме косо срезанной трубки, и берется проба взрывчатого вещества (BВ). В экспресс анализаторе, определяется тип ВВ и по таблицам с учетом температуры выбирается растворитель.

Допускается сверление 2 отверстий под 2 штуцера: - вход, - выход. 
В отверстие вводится штуцер, имеющий канал подачи растворителя и второй канал удаления раствора. Из емкости с растворителем с помощью насоса по шлангу подается растворитель по каналу подачи растворителя. Через второе отверстие в штуцере идет выливание по другому шлангу в другую емкость. Плотность растворителя изменяется, и можно приблизительно знать сколько выбрано ВВ взвешивая полную емкость с раствором. Вымывание производится до момента, когда оставшаяся часть ВВ не представляет сильного разрушающегося действия.

Если ВВ на основе селитр и органического вещества или с алюминиевой или магниевой пудрой, то простое намокание ВВ приведет к обезвреживанию боеприпаса. Взрыв всего ВВ не будет, а первичный и вторичный детонатор в виде толовой шашки особой опасности для сооружений не представляет.

Ниже приведено описание заявки на изобретение, на которую получен патент.

ФЕДЕРАЛЬНАЯ СЛУЖБА

ПО ИНТЕЛЛЕКТУАЛЬНОЙ СОБСТВЕННОСТИ,

ПАТЕНТАМ И TОВАРНЫМ ЗНАКАМ (19) RU (11) 2418262 (13) C2

(51) МПК

F42B33/06 (2006.01)

(12) ОПИСАНИЕ ИЗОБРЕТЕНИЯ К ПАТЕНТУ.

Статус: по данным на 17.10.2013 - действует

Пошлина: не взимаются - статья 1366 ГК РФ

На основании пункта 1 статьи 1366 части четвертой Гражданского кодекса Российской Федерации патентообладатель обязуется заключить договор об отчуждении патента на условиях, соответствующих установившейся практике, с любым гражданином Российской Федерации или российским юридическим лицом, кто первым изъявил такое желание и уведомил об этом патентообладателя и федеральный орган исполнительной власти по интеллектуальной собственности.

(21), (22) Заявка: 2009146777/11, 16.12.2009

(24) Дата начала отсчета срока действия патента: 16.12.2009

Приоритет(ы):

(22) Дата подачи заявки: 16.12.2009

(43) Дата публикации заявки: 27.04.2010

(45) Опубликовано: 10.05.2011 
(56) Список документов, цитированных в отчете о поиске:

СМИРНОВ Л.А., ТИНЬКОВ О.В. Конверсия. Часть IV. Утилизация снятых с вооружения боеприпасов и твердотопливных ракет. M., 1996, с.79-80. SU 1766686 A1, 07.10.1992. SU 303199 A, 13.05.1971. RU 2123933 C1, 27.12.1998. EA 1061 B1, 30.10.2000. DE 4010757 A, 01.08.1991.

Адрес для переписки:

394088, г.Воронеж, ул. ген. Лизюкова, 99, кв.47, А.И. Голодяеву

(72) Автор(ы):

Голодяев Александр Иванович (RU)

(73) Патентообладатель(и):

Голодяев Александр Иванович (RU)

(54) СПОСОБ РАЗМИНИРОВАНИЯ ФУГАСНЫХ БОЕПРИПАСОВ, УСТАНОВЛЕННЫХ С ЭЛЕМЕНТАМИ НЕИЗВЛЕКАЕМОСТИ

\section{(57) Рефрерат:}

Изобретение относится к способам разминирования фругасных боеприпасов, установленных с элементами без извлечения. Способ заключается в том, что в корпусе (1) боеприпаса (2) сверлятся отверстия (3) для штуцеров подвода (4) и штуцеров отвода (5) растворителя (6). Штуцера подвода (4) растворителя (6) соединены шлангами (7) с гидравлическим насосом (8), который соединен шлангами (7) с емкостью (9) с растворителем (6). В другую емкость (10) от штуцеров отвода (5) растворителя (6) по шлангам (7) поступает насыщенный раствор взрывчатки (11) из боеприпаса (2). Отверстия (3) на корпусе (1) боеприпаса (2) располагаются парами так, чтобы каналы (12) отверстий (3) штуцеров подвода (4) и отвода (5) растворителя (6) пересекались для свободного прохода растворителя (6). Повышается безопасность процесса разминирования. 1 ил.

Известно изобретение «СИСТЕМА РАЗМИНИРОВАНИЯ» ФЕДЕРАЛЬНАЯ СЛУЖБА ПО ИНТЕЛЛЕКТУАЛЬНОЙ СОБСТВЕННОСТИ, ПАТЕНТАM И TOBAPHЫM 3HAKAM (19) RU (11) 99105118 (13) A, МПК 7 F41H 11/16, Заявка: 99105118/02, 06.08.1997, Дата публикации заявки: 20.01.2001, Дата перевода заявки РСТ на национальную фразу: 17.03.1999. Заявка РСТ: ЕР 97/04289 (06.08.1997), Публикация PCT: WO 98/08043 (26.02.1998), Адрес для переписки: 129010, Москва, ул.Большая Спасская 25, стр.3, ООО "Городисский и Партнеры", Емельянову Е.И., Заявитель(и): ФЛЕНСБУРГЕР ФАРЦОЙГБАУ ГЕЗЕЛЛЬШАФТ МБХ (DE), 
Автор(Ы): ЭНГЕЛЬБРЕХТ Уве (DE), КАМПЕР Йорг (DE), Патентный поверенный: Емельянов Евгений Иванович.

\section{Рефрерат}

1. Устройство для разминирования, состоящее из транспортного средства (12) для разминирования, оснащенного модифицированным бронированным транспортным средством (16) и двигателями жидкого топлива, на передней стороне которого предусмотрено выполненное с возможностью поворота вокруг горизонтальной оси (40) фронтальное навесное устройство для размещения фрезерного барабана (26), который на своей окружной поверхности имеет режущие и разламывающие инструменты $(28,50)$, отличающееся тем, что предусмотрен приводной блок (58) из первого приводного двигателя (60) и второго приводного двигателя (78), которые по выбору используются как отдельные агрегаты или как совместный блок, что первый приводной двигатель (60) через сцепление (64) с переходным кольцом (68) действует на раздаточную коробку (66) для насосов, которая в свою очередь приводит в действие масляные насосы (70), которые нагружают двигатели (72) для перемещения, воздействующие на понижающие передачи боковых редукторов, что второй приводной двигатель (78) через сцепление (82) с переходным кольцом воздействует на вторую раздаточную коробку (84) для насосов, которая соединена с масляными насосами, приводящими в действие соответствующие фррезерные барабаны (26), что вместо танковой башни на бронированном транспортном средстве (16) оборудована кабина (18) водителя, которая установлена на поглощающие ударное воздействие демпфирующие элементы (20), расположенные по углам прямоугольной в поперечном сечении кабины (18) водителя со стороны дна, и что на транспортном средстве (12) для разминирования предусмотрено заднее навесное устройство с фрезерным барабаном, которое образует устройство для повторного разминирования с используемым фрезерным барабаном (44), за которым расположено транспортировочное и просеивающее устройство (56).

2. Устройство для разминирования по п.1, отличающееся тем, что радиально выступающие из фрезерных барабанов $(26,44)$ режущие и разламывающие инструменты $(28,50)$ расположены на внешней поверхности $(30,52)$ фрезерных барабанов однозаходно или многозаходно по винтовой линии.

3. Устройство для разминирования по п.1, отличающееся тем, что два приводных двигателя расположены друг над другом по вертикале.

4. Устройство для разминирования по п.1 или 3, отличающееся тем, что масляные насосы включены последовательно. 
5. Устройство для разминирования по п.1 или 3, отличающееся тем, что масляные насосы включены последовательно попарно.

6. Устройство для разминирования по п.1, отличающееся тем, что надземная часть шасси и/или внутренняя часть ванны имеют дополнительную броню $(22,24)$.

7. Устройство для разминирования по п.1 или 2, отличающееся тем, что фррезерный барабан (26) во фронтальном навесном устройстве и/или фррезерный барабан (44) с приданным ему транспортировочным и просеивающим устройством (56) в заднем навесном устройстве закреплены временно на транспортном средстве (12) для разминирования (аналог).

8. Устройство для разминирования по п.1, отличающееся тем, что сцепление $(64,82)$ за приводным двигателем $(60,78)$ со стороны входа снабжено маховиком (аналог).

Недостатки: невозможность разминирования боеприпасов большой мощности, установленных с элементами без извлечения.

Известно ИзобретенИе «СПОСОБ РАЗМИНИРОВАНИЯ МЕСТНОСТИ॥ ФЕДЕРАЛЬНАЯ СЛУЖБА ПО ИНТЕЛЛЕКТУАЛЬНОЙ СОБСТВЕННОСТИ, ПАТЕНТАМ И ТОВАРНЫМ ЗНАКАМ, RU 2003110838 A, МПК 7 F41H 11/16. Заявка: 2003110838/02, 15.04.2003, Дата отзыва заявки: 22.05.2004, Дата публикации заявки: 27.12.2004, Адрес для переписки: 454010, г.Челябинск, ОАО "ФНПЦ "Станкомаш", Начальник ОТО, Ю.Д.Болдыреву, Заявитель(и): ОАО "ФНПЦ "Станкомаш" (RU). Автор(ы): Сердцев Николай Иванович (RU), Тарасов Анатолий Игнатьевич (RU), Камшилов Геннадий Дмитриевич (RU), Шальтис Владимир Викторович (RU), Зиновьев Владимир Петрович $(R U)$, Ширинкин Валерий Алексеевич (RU), Котенко Андрей Владимирович (RU).

1. Способ разминирования местности от взрывоопасных предметов, включающий воздействие рабочими органами посредством фризического поля на мины и боеприпасы и удаления последних с заминированного участка, отличающийся тем, что воздействие рабочими органами осуществляется посредством магнитного поля, создаваемого источником магнитного поля, поднимающим предметы из ферритового материала, в том числе взрывоопасные, находящиеся в грунте и на его поверхности, с фиксацией поднятых предметов на поверхности источника магнитного поля, причем под воздействием магнитного поля предметы, зафиксированные на поверхности магнитного источника, удерживаются в течение определенного времени, перемещаются в заданную зону и после снятия магнитного по- 
ля сбрасываются в места складирования для последующего транспортирования или обезвреживания в процессе разминирования (аналог).

Недостатки: невозможность разминирования боеприпасов большой мощности, установленных с элементами неизвлекаемости.

Известен способ извлечения взрывчатых веществ методом по выплавлению тротила из авиационных бомб и термопластическому выдавливанию взрывчатой начинки из глубинных бомб.

«Севастопольская газета» Тел./фракс редакции: +38 (0692) 5574-66, E-mail: info@gazeta.sebastopol.ua, 99011, Украина, Севастополь, ул.Батумская, 34, 6 от 5 февраля 2004.

«Проблемой утилизации и переработки в свое время занималось Министерство обороны СССР. Под каждый вид боеприпасов стремились создать определенную технологию. К примеру, была разработана технология утилизации артиллерийских снарядов с латунной гильзой, которая составляла 50 процентов от массы выстрела. А на одном из химических заводов внедрили установку по выплавлению тротила из авиационных бомб и термопластическому выдавливанию взрывчатой начинки из глубинных бомб» (аналог).

Недостатки: высокая вероятность срабатывания взрывателя при нагреве боеприпаса. Необходимость перемещения боеприпаса, невозможность разминирования боеприпасов большой мощности, установленных с элементами без извлечения. Во время извлечения взрывчатки она находится рядом с основным зарядом и создает условия общего взрыва при детонации боеприпаса.

Известен способ разминирования методом выплавления взрывчатки из боеприпаса, описанный: Старинов Илья. "Человек-легенда XX века"

http://www.agentura.ru/dossier/russia/people/starinov/webmaster@agentura.ru

(САгентура, 2000-2004 гг. «Вблизи городов и сел находилось много неразорвавшихся снарядов. Старинов использовал каждый случай, чтобы исследовать устройство взрывателей. Первые опыты по вплавлению взрывчатки из снарядов и бомб дали положительные результаты» (прототип).

Недостатки: высокая вероятность срабатывания взрывателя при нагреве боеприпаса. Необходимость перемещения боеприпаса, невозможность разминирования боеприпасов большой мощности, 
установленных с элементами без извлечения. Во время извлечения взрывчатки она находится рядом с основным зарядом и создает условия общего взрыва при детонации боеприпаса.

Технический результат: эффрективное извлечение взрывчатого вещества из всего объема боеприпаса не перемещая его с места, лишая боеприпас возможности детонировать всем зарядом, и возможность разминирования боеприпасов имеющих установленные элементы без извлечения и высокая безопасность работы.

Поставленная задача решается тем, что в корпусе боеприпаса сверлятся отверстия для штуцеров для подвода и штуцеров отвода растворителя, причем штуцера подвода растворителя соединены шлангами с гидравлическим насосом, который соединен шлангами с емкостью с растворителем, а в другую емкость от штуцеров отвода растворителя по шлангам поступает насыщенный раствор взрывчатки из боеприпаса, причем отверстия на корпусе боеприпаса располагаются парами так, чтобы каналы отверстий штуцеров подвода и отвода растворителя пересекались для свободного прохода растворителя. Все основные взрывчатые вещества (тротил, гексоген, тетрил и другие на основе нитрования органических веществ) легко растворяются органическими растворителями (бутилацет, ацетон, дихлорэтан, трихлорэтилен и др.). Часть взрывчатых веществ создается из механической смеси различных веществ. Например «аммонит» - смесь тротила и аммиачной селитры с горючим материалом и пластификатором. Большинство компонентов этих смесей составляют соли нитратов или бертолетова соль. Они прекрасно растворяются в воде. При промывке таких боеприпасов сначала вымываются водой соли нитратов, а потом вымываются органическим растворителем остальные компоненты взрывчатки. Какой именно состав и способ промывки определяется экспресс-анализом при взятии образца при сверлении каналов для промывки в корпусе боеприпаса. Вес растворенной взрывчатки определяется по плотности и объему насыщенного раствора.

На чертеже изображен способ разминирования фругасных боеприпасов, установленных с элементами без извлечения.

\section{Статика}

Способ разминирования фугасных боеприпасов, установленных с элементами без извлечения, отличается тем, что в корпусе боеприпаса сверлятся отверстия для штуцеров для подвода и штуцеров отвода растворителя, причем штуцера подвода растворителя соединены шлангами с гидравлическим насосом, который соединен шлан- 
гами с емкостью с растворителем, а в другую емкость от штуцеров отвода растворителя по шлангам поступает насыщенный раствор взрывчатки из боеприпаса, причем отверстия на корпусе боеприпаса располагаются парами так, чтобы каналы отверстий штуцеров подвода и отвода растворителя пересекались для свободного прохода растворителя.

\section{Работа}

Способ разминирования фугасных боеприпасов, установленных с элементами без извлечения, отличается тем, что в корпусе (1) боеприпаса (2) сверлятся отверстия (3) для штуцеров для подвода (4) и штуцеров отвода (5) растворителя (6), причем штуцера подвода (4) растворителя (6) соединены шлангами (7) с гидравлическим насосом (8), который соединен шлангами (7) с емкостью (9) с растворителем (6), а в другую емкость (10) от штуцеров отвода (5) растворителя (5) по шлангам (7) поступает насыщенный раствор взрывчатки (11) из боеприпаса (2), причем отверстия (3) на корпусе (1) боеприпаса (2) располагаются парами так, чтобы каналы (12) отверстий (3) штуцеров подвода (4) и отвода (5) растворителя (6) пересекались для свободного прохода растворителя (6). Все основные взрывчатые вещества (13) (тротил, гексоген, тетрил и другие на основе нитрования органических веществ) легко растворяются органическими растворителями (6) (бутилацет, ацетон, дихлорэтан, трихлорэтилен и др.) Часть взрывчатых веществ (13) создается из механической смеси различных веществ. Например, «аммонит» - смесь тротила и аммиачной селитры с горючим материалом и пластификатором. Большинство компонентов этих смесей составляют соли нитратов или бертолетова соль. Они прекрасно растворяются в воде. При промывке таких боеприпасов сначала вымываются водой (14) соли нитратов, а потом вымываются органическим растворителем (6) остальные компоненты взрывчатки (13). Какой именно состав и способ промывки определяется экспресс-анализом при взятии образца при сверлении каналов (12) для промывки в корпусе (1) боеприпаса (2).

Технико-экономические показатели у заявленного изобретения значительно выше, т.к. оно обеспечивает разминирование без подрыва на месте фругасных боеприпасов с элементами без извлечения.

Была разминирована граната Ф1 времен Второй Мировой войны методом вымывания тротила растворителем бутилацетат. Процесс занял 10 минут. 


\section{Формула изобретения}

Способ разминирования фугасных боеприпасов, установленных с элементами без извлечения, отличающийся тем, что в корпусе боеприпаса сверлятся отверстия для штуцеров подвода и штуцеров отвода растворителя, причем штуцера подвода растворителя соединены шлангами с гидравлическим насосом, который соединен шлангами с емкостью с растворителем, а в другую емкость от штуцеров отвода растворителя по шлангам поступает насыщенный раствор взрывчатки из боеприпаса, причем отверстия на корпусе боеприпаса располагаются парами так, чтобы каналы отверстий штуцеров подвода и отвода растворителя пересекались для свободного прохода растворителя.

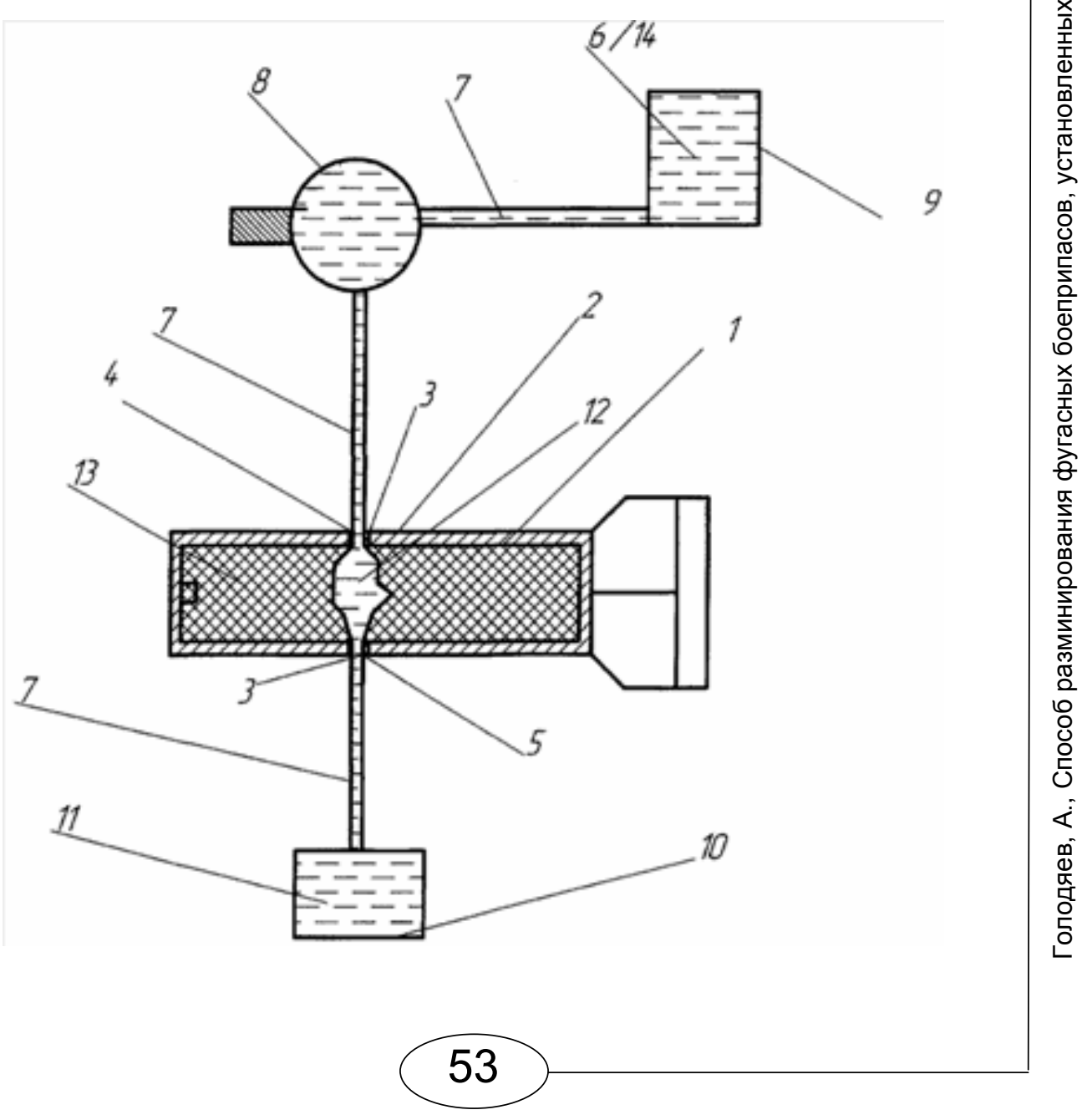


Перечень позиций

1 - корпус

2 - боеприпас

3 - отверстие

4 - штуцер для подвода растворителя

5 - штуцер отвода растворителя

6 - растворитель

7 - шланг

8 - гидравлический насос

9 - емкость

10 - емкость с насыщенным раствором взрывчатки (11)

11 - насыщенный раствор взрывчатки

12 - канал

13 - взрывчатое вещество

14 - вода

Лumepamypa/Literature:

Шидловский, А.А. 1973. Основы пиротехники.

Матвейчук, В.В. 2005. Взрывное дело (Внимание, взрыв): Учебно-практическое пособие.М: Академический Проект., стр. 512.

Мингулина, Э.И., Масленникова, Г.Н., \& Коровин, Н.В. 1990. Курс общей химии. Издательство: Высшая школа.

Обоснование необходимости утилизации списанных боеприпасов (введение) Скачано c http://do.gendocs.ru/docs/index-339053.html?page=2

\section{RAZMINIRANJE EKSPLOZIVNIH BOJEVIH NAPRAVA} SA ELEMENTIMA KOJI SE NE IZVLAČE

Aleksandar Ivanovič Golodjaev

Kandidat za zvanje magistra nauka na VGTU,

Voronjež, Rusija

OBLAST: materijali

VRSTA ČLANKA: pregledni članak

\section{Sažetak:}

Primena načina razminiranja putem ispiranja eksplozivne materije rastvorom utiče da se sačuvaju velike materijalne vrednosti, a smanjuje $i$ rizik od povreda pirotehniča, čiji su poslovi vezani za premeštaj municije do mesta reciklaže. Troškovi za specijalnu vrstu opreme za takve svrhe su minimalni. Tehnologiju je lako automatizovati primenom elektronskog 
i daljinski kontrolisanog procesa bušenja koji smanjuje rizik od eksplozije na minimum. Ovakav način razminiranja biće efikasan, naročito u zonama dejstava protiv partizanskog minskog rata.

Ključne reči: eksplozivne bojeve naprave, razminiranje.

\section{NEUTRALISING ORDNANCE WITH NON-EXTENDING ELEMENTS}

Alexander Ivanovich Golodyaev

Competitor for the title of Candidate of Sciences in Vilnius Gediminas

Technical University, Voronez, Russia

FIELD: Materials

ARTICLE TYPE: Review Paper

\section{Summary:}

The method of neutralising ordnance by rinsing explosive materials with a solution enables significant cost saving while reducing the risk pyrotechnic personnel is exposed to, especially during ammunition transport to recycling sites. Costs for necessary special equipment are minimal. The technology is easy to be automated using an electronic and remotely controlled drilling process which reduces the risk of explosion to the minimum. This demining method will prove effective especially for operations against guerrilla mine warfare.

Key words: ordnance, demining.

Дата получения работы/Paper received on: 25. 10. 2013.

Дата получения исправленной версии работы/Manuscript corrections submitted on:

05. 12. 2013.

Дата окончательного согласования работы /Paper accepted for publishing on:

07. 12. 2013. 